\title{
A note on the profits of retail firms purchasing multiple inputs
}

\author{
Keita Yamane ${ }^{a^{*}}$
}

${ }^{a}$ Graduate School of Economics, Kobe University, 2-1 Rokkodai, Nada, Kobe 657-8501, Japan

\begin{tabular}{|c|c|}
\hline CHRON I C L E & A B S T RACT \\
\hline $\begin{array}{l}\text { Article history: } \\
\text { Received: November } 26,2017 \\
\text { Received in revised format: No- } \\
\text { vember } 26,2017 \\
\text { Accepted: December } 12,2017 \\
\text { Available online: } \\
\text { December } 12,2017\end{array}$ & $\begin{array}{l}\text { This paper uses the Nash bargaining model to examine the effects of the distribution system on } \\
\text { firms purchasing multiple inputs. We show that network combination, that is, vertical integration } \\
\text { between a manufacturer and a retail firm, does not always bring enterprise superiority to a non- } \\
\text { integrated firm. Although classical economic theory articulates that vertically integrated firms typ- } \\
\text { ically have an advantage over non-integrated firms in profits, as the former can eliminate double } \\
\text { marginalization, this is not always the case if we consider a situation of multiple inputs trading. }\end{array}$ \\
\hline $\begin{array}{l}\text { Keywords: } \\
\text { Cournot competition } \\
\text { Multiple inputs } \\
\text { Nash bargaining } \\
\text { Ranking of profits }\end{array}$ & (O) 2018 by the authors; licensee Growing Science, Canada \\
\hline
\end{tabular}

\section{Introduction}

Classical economic theory posits that when an upstream firm and a downstream firm integrate, prices decrease, and the profits of the new firm surpass the sum of the profits of the firms, when they were separate. This logic - the elimination of double marginalization - was initially suggested by Spengler (1950) and has strongly supported vertical integration (VI) activity in various situations and industries.

However, researchers have shown less interest in cases of multiple inputs trading in confirming the validity of the elimination of double marginalization. The reasons may be that researchers have mainly focused on the number of firms and cost structures. However, as we recognize without relying on any specialized knowledge, a key point that determines market performance is the bargaining power between firms. This is particularly important, for example, for the distribution system. Thus, considering the real business trading world, we should not exclusively discuss the economic aspects, such as the number of firms or cost function. In this paper, we consider whether a VI advantage appears using a multiple-input bargaining model.

We present some related literature. First, a few studies consider the meaning of VI. Salinger (1988) is

\footnotetext{
* Corresponding author. Tel.: +81-78-803-7247

E-mail address: pm08yamane@gmail.com (K. Yamane) 
one of the prominent researchers to show that excess VI can worsen performance. Additionally, Salinger (1991) treats the case of monopolistic downstream firm integration with an upstream firm with twounit inputs, and he analyzes the economic effects on wholesale prices. Buzzell (1983) considers whether VI adds or decreases firms' profits with empirical data, and he explains that it can have negative effects. Some research considers the trade of inputs between upstream and downstream in the framework of Nash bargaining. Binmore et al. (1986) were among the first to present a method to solve the Nash bargaining problems through Nash product-maximization rather than an axiom. Naylor (2002) analyzes the characteristics of industry profits within a one-unit input model. Chen et al. (2016) show that the intensification of bargaining power downstream (countervailing power) can improve consumer surplus. Laussel (2008) analyzes the incentives of VI in cases of multiple inputs trading, but he focuses on the number of integrated upstream firms rather than bargaining power. We focus on bargaining power; therefore, our paper complements the research of Laussel (2008). Finally, Chongvilaivan (2015) considers a situation in which one of the inputs is supplied by a monopolistic upstream firm and confirms whether a downstream firm's VI with the upstream firm can foreclose rival firms.

These studies include suggestive ideas; however, there seems to be less interest in firms' profits, regardless of their importance from a managerial perspective. In this paper, we show that VI between an upstream firm (e.g., a manufacturer) and a downstream firm (e.g., a retail firm) does not always bring enterprise superiority to the non-integrated firm. This finding on profit ranking will give non-integrated, small firms a strong incentive to enter the market and compete fairly with integrated firms, while it would be a warning for policymakers to not overestimate the merit of vertical integration. In addition, the finding suggests the necessity of empirically measuring the bargaining power of upstream and downstream firms.

The paper is organized as follows. In section 2, we present and solve the model. In section 3 , we describe the main results, and Section 4 concludes the study.

\section{Model}

\subsection{Preliminaries}

We consider a two-tier market with upstream and downstream suppliers. Upstream, there are two manufacturers. The first manufacturer, denoted by $M_{x_{1}}$, produces input $x_{1}$, and the second manufacturer, denoted by $M_{x_{2}}$, produces input $x_{2}$. Downstream, there are two retail firms, denoted by $R_{1}$ and $R_{2}$. Retail firms can produce a final good using both $x_{1}$ and $x_{2}$. Thus, each of the retail firms must trade with both the manufacturers. We suppose that $R_{1}$ trades with $M_{x_{1}}^{R_{1}}$ and $M_{x_{2}}^{R_{1}}$, and $R_{2}$ trades with $M_{x_{1}}^{R_{2}}$ and $M_{x_{2}}^{R_{2}}$.

A crucial difference between the retail firms is that they are asymmetric in vertical structures. $R_{1}$ owns (namely, vertically integrates) $M_{x_{1}}^{R_{1}}$ and does not own $M_{x_{2}}^{R_{1}}$, while $R_{2}$ does not own either $M_{x_{1}}^{R_{2}}$ or $M_{x_{2}}^{R_{2}}$. Thus, $R_{1}$ purchases only $x_{2}$ from $M_{x_{2}}^{R_{1}}$ while $R_{2}$ must purchase both $x_{1}$ and $x_{2}$ from the manufactures. The input price from $R_{1}$ to $M_{x_{2}}$ is denoted by $w_{12}$, and prices from $R_{2}$ to $M_{x_{1}}^{R_{2}}$ and $M_{x_{2}}^{R_{2}}$ are denoted by $w_{21}$ and $w_{22}$, respectively. These prices are determined through negotiations. Throughout the paper, we apply the following assumption.

Assumption. If breakdowns occur, renegotiations with other firms do not take place. That is, the concerned parties do not realize any profits from breakdowns.

This assumption is not only for simplicity but also to emphasize that the result obtained in this paper is counterintuitive. The game is as follows. In the first stage, input prices are determined through Nash bargaining under the given bargaining powers. In the second stage, retail firms compete on quantity. 
We solve this game by backward induction.

\subsection{Equilibrium}

At first, we consider the second stage. Inverse demand function is given by $p=a-Q$, where $p, a$, and $Q\left(=q_{1}+q_{2}\right)$ indicate consumer price, demand scale, and total output, respectively. In addition, $a$ is assumed to be sufficiently large. Then, profit functions of retail firms are written as follows:

$\pi_{R_{1}}=\left(p-w_{12}\right) q_{1}$

$\pi_{R_{2}}=\left(p-w_{21}-w_{22}\right) q_{2}$.

By first-order conditions, the productions of the retail firms in equilibrium are $q_{1}^{[2]}=\frac{a-2 w_{12}+w_{21}+w_{22}}{3}$ and $q_{2}^{[2]}=\frac{a+w_{12}-2 w_{21}-2 w_{22}}{3}$. Thus, profit functions of retail firms in this stage are rewritten as follows:

$\pi_{R_{1}}^{[2]}=\frac{\left(a-2 w_{12}+w_{21}+w_{22}\right)^{2}}{9}$,

$\pi_{R_{2}}^{[2]}=\frac{\left(a+w_{12}-2 w_{21}-2 w_{22}\right)^{2}}{9}$.

Next, we consider the first stage. The production costs of manufactures are normalized to $0 .{ }^{1}$ The bargaining powers of $R_{1}$ to $M_{x_{2}}^{R_{1}}, R_{2}$ to $M_{x_{1}}^{R_{2}}$, and $R_{2}$ to $M_{x_{2}}^{R_{2}}$ are, given by $r, s, t \in[0,1]$, respectively. Then, the Nash products are written as follows:

$$
\begin{aligned}
& B_{12}=\left[\pi_{R_{1}}^{[2]}\right]^{r}\left[w_{12} q_{1}^{[2]}\right]^{1-r}, \\
& B_{21}=\left[\pi_{R_{2}}^{[2]}\right]^{S}\left[w_{21} q_{2}^{[2]}\right]^{1-s}, \\
& B_{22}=\left[\pi_{R_{2}}^{[2]}\right]^{t}\left[w_{22} q_{2}^{[2]}\right]^{1-t} .
\end{aligned}
$$

$B_{i j}$ is maximized with respect to $w_{i j}$, for all $(i, j)=(1,2),(2,1),(2,2)$. Then, the input prices in equilibrium are obtained as follows:

$$
\begin{aligned}
w_{12} & =\frac{a(1-r)(4+s+t-2 s t)}{11+r+4 s+4 t-3 s t-r s t^{\prime}} \\
w_{21} & =\frac{a(5-r)(1-s)(1+t)}{2(11+r+4 s+4 t-3 s t-r s t)}, \\
w_{22} & =\frac{a(5-r)(1+s)(1-t)}{2(11+r+4 s+4 t-3 s t-r s t)} .
\end{aligned}
$$

Substituting these into (3) and (4), we obtain the equilibrium profits as follows:

$$
\begin{aligned}
& \pi_{R_{1}}^{e}=\left[\frac{2 a(1+r)(4+s+t-2 s t)}{3(11+r+4 s+4 t-3 s t-r s t)}\right]^{2}, \\
& \pi_{R_{2}}^{e}=\left[\frac{a(5-r)(1+s)(1+t)}{3(11+r+4 s+4 t-3 s t-r s t)}\right]^{2} .
\end{aligned}
$$

\section{Results and discussion}

First, we confirm the effect of the bargaining powers to consumer welfare, namely, retail prices.

${ }^{1}$ We implicitly assume that upstream firms are not competitive (i.e., in quantity) because the model adding upstream competition correctly describes the successive Cournot duopoly à la Salinger (1988), while the main result still holds in our simplified model. 
Proposition 1. The increase in bargaining powers improves consumer welfare.

Proof. Since the model is a homogenous goods market, we only have to check the change in retail price. The retail price is obtained as follows:

$$
p^{e}=\frac{a(5-r)(4+s+t-2 s t)}{3(11+r+4 s+4 t-3 s t-r s t)} \text {. }
$$

Differentiating this with respect to $r, s$, and $t$ yields,

$$
\begin{aligned}
& \frac{\partial p^{e}}{\partial r}=-\frac{4 a(4+s+t-2 s t)^{2}}{3(11+r+4 s+4 t-3 s t-r s t)^{2}}<0, \\
& \frac{\partial p^{e}}{\partial s}=-\frac{a(5-r)^{2}(1+t)^{2}}{3(11+r+4 s+4 t-3 s t-r s t)^{2}}<0, \\
& \frac{\partial p^{e}}{\partial t}=-\frac{a(5-r)^{2}(1+s)^{2}}{3(11+r+4 s+4 t-3 s t-r s t)^{2}}<0 .
\end{aligned}
$$

These results are quite intuitive and depend on the effect of the change in input prices. Differentiating (8), (9), and (10) with respect to $r, s$, and $t$, respectively, we indeed obtain the following:

$$
\begin{aligned}
\frac{\partial w_{12}}{\partial r} & =-\frac{4 a(3+s+t-s t)(4+s+t-2 s t)^{2}}{(11+r+4 s+4 t-3 s t-r s t)^{2}}<0, \\
\frac{\partial w_{21}}{\partial s} & =-\frac{a(5-r)(1+t)(15+r+t-r t)}{2(11+r+4 s+4 t-3 s t-r s t)^{2}}<0, \\
\frac{\partial w_{22}}{\partial t} & =-\frac{a(5-r)(1+s)(15+r+s-s t)}{2(11+r+4 s+4 t-3 s t-r s t)^{2}}<0 .
\end{aligned}
$$

Next, for the magnitude relation between $\pi_{R_{1}}^{e}$ and $\pi_{R_{2}}^{e}$, we expect that the former dominates the latter because $R_{1}$ is more efficient than $R_{2}$ in purchasing inputs. However, this is not always the case. The following statement summarizes the result.

Proposition 2. The combinations of $(r, s, t)$ exist, which yields $\pi_{R_{2}}^{e}>\pi_{R_{1}}^{e}$.

Proof. The term that determines the sign of $\pi_{R_{2}}^{e}-\pi_{R_{1}}^{e}$ is

$$
z=(s t-s-t-3) r+3 s t+s+t-1 \text {. }
$$

If this term is positive, the relation, $\pi_{R_{2}}^{e}>\pi_{R_{1}}^{e}$, holds. $z$ is a linear and decreasing function in $r$. When taking $r_{1}$ such that $z=0$, then $r_{1}=(3 s t+s+t-1) /(3+s+t-s t)$, which is lower than 1. Hence, if $\left(s^{\prime}, t^{\prime}\right)$ is large enough with $r_{1}>0$ and $r<r_{1}\left(s^{\prime}, t^{\prime}\right), z>0$ is satisfied.

The logic behind this phenomenon is as follows. If the process that determines input prices is depicted in a successive oligopoly model, the usual forecast, $\pi_{R_{1}}^{e}>\pi_{R_{2}}^{e}$, always holds, as the model tacitly assumes $r=s=t=0$. However, this is not always the case if retail firms have some degree of bargaining power. Thus, $R_{2}$ 's strong bargaining power with both $M_{1}$ and $M_{2}$ alleviates the inefficiency of the vertical separation (double marginalization), whereas $R_{1}$ 's weak bargaining power against $M_{2}$ reduces the efficiency of the vertical integration. We explain this in more detail with some numerical examples of $(r, s, t)$. For instance, defining $\Delta \pi \equiv \pi_{R_{2}}^{e}-\pi_{R_{1}}^{e},(0.1,0.1,0.1)$ or $(0.5,0.5,0.5)$ does not support the 
proposition because the former yields $\Delta \pi=-0.03897 a^{2}<0$ and the latter yields $\Delta \pi=$ $-0.04142 a^{2}<0$. On the other hand, combinations such as $(0.1,0.3,0.6)$ and $(0.5,0.7,0.8)$ are shown in the table below, support the proposition.

Table 1

Numerical examples of $(r, s, t)$ supporting Proposition 2

\begin{tabular}{cccc}
\hline $\mathrm{r}$ & $\mathrm{s}$ & $\mathrm{t}$ & $\left(\pi_{R_{2}}^{e}-\pi_{R_{1}}^{e}\right) / a^{2}$ \\
\hline 0.1 & 0.2 & 0.8 & 0.00313 \\
0.1 & 0.3 & 0.6 & 0.00229 \\
0.3 & 0.4 & 0.9 & 0.00687 \\
0.3 & 0.5 & 0.7 & 0.00336 \\
0.5 & 0.6 & 0.9 & 0.00516 \\
0.5 & 0.7 & 0.8 & 0.00780 \\
0.7 & 0.8 & 0.9 & 0.00287 \\
0.7 & 0.9 & 0.78 & 0.00005 \\
0.9 & 0.97 & 0.93 & 0.00033 \\
0.9 & 0.98 & 0.92 & 0.00025 \\
\hline
\end{tabular}

\section{Conclusion}

In the classic model in which upstream manufacturers produce single inputs and supply them to downstream retail firms, we have explained that vertically integrated retail firms usually dominate non-integrated retail firms in profits. However, in a market where retail firms produce final goods using multiple inputs, we have found that the described scenario is not always the case. In other words, non-integrated retail firms (small firms) can surpass integrated firms (large firms) in profits or market share if the former firms strengthen their bargaining power.

We conclude the paper by presenting three directions for future research. First, we must relax the assumption in breakdowns since renegotiations often occur in reality; we did not address this here because of computational limitations. Second, we must consider the price competition case rather than quantity competition because the effects of bargaining power on market performance can differ between the two, as noted by Ungern-Sternberg (1996). Third, we must reconsider competition policy in vertically related markets.

\section{Acknowledgements}

The author is grateful to Tomomichi Mizuno (Kobe University), Takashi Yanagawa (Kobe University), and the anonymous referees for their valuable comments and suggestions.

\section{References}

Binmore, K., Rubinstein, A., \& Wolinsky, A. (1986). The Nash bargaining solution in economic modelling. The RAND Journal of Economics, 17(2), 176-188.

Buzzell, R. D. (1983). Is vertical integration profitable? Harvard Business Review, 61(1), 92-102.

Chen, Z., Ding, H., \& Liu, Z. (2016). Downstream competition and the effects of buyer power. Review of Industrial Organization, 49, 1-23.

Chongvilaivan, A. (2015). Upstream foreclosure decisions under successive monopoly structure. Managerial and Decision Economics, 36, 528-534.

Laussel, D. (2008). Buying back subcontractors: The strategic limits of backward integration. Journal of Economics \& Management Strategy, 17(4), 895-911.

Naylor, R. A. (2002). Industry profits and competition under bilateral oligopoly, Economics Letters. 
$77,169-175$.

Salinger, M. A. (1988). Vertical mergers and market foreclosure. The Quarterly Journal of Economics, 103(2), 345-356.

Salinger, M. A. (1991). Vertical mergers in multi-product industries and Edgeworth's paradox of taxation. The Journal of Industrial Economics, 39(5), 545-556.

Spengler, J. J. (1950). Vertical integration and antitrust policy. Journal of Political Economy, 58(4), 347-352.

Ungern-Sternberg, T. (1996). Countervailing power revisited. International Journal of Industrial Organization, 14, 507-520.

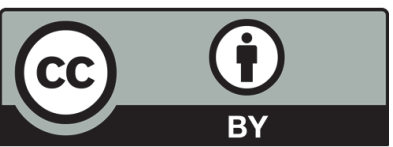

(C) 2018 by the authors; licensee Growing Science, Canada. This is an open access article distributed under the terms and conditions of the Creative Commons Attribution (CC-BY) license (http://creativecommons.org/licenses/by/4.0/). 